\title{
A GESTÃO DE ÁREAS CONTAMINADAS EM MINAS GERAIS: O LICENCIAMENTO COMO INSTRUMENTO PREVENTIVO
}

\author{
Gabriela Cristina Barbosa Brito \\ Mestranda em Saneamento, Meio Ambiente e Recursos Hídricos pela \\ Universidade Federal de Minas Gerais - UFMG \\ gabrielacbbrito@gmail.com
}

Fernanda Carla Wasner Vasconcelos

Doutora em Ciência do Solo pela Universidade Federal de Lavras - UFLA fernanda.coordenadora@prof.una.br

\section{RESUMO}

No Brasil, é relativamente recente o conceito de áreas contaminadas. A contaminação do solo envolve riscos à saúde pública e aos ecossistemas. Observa-se, com muita preocupação, o setor petrolífero, cuja atividade é potencialmente contaminadora, principalmente por vazamentos de tanques de armazenamento subterrâneos em postos de combustíveis. No ano de 2010, foram listadas 439 áreas contaminadas no Estado de Minas Gerais, das quais 80\% estavam relacionadas com as atividades de postos de abastecimento. Este trabalho tem como objetivo analisar o gerenciamento de áreas contaminadas no Estado de Minas Gerais, além de descrever a importância do licenciamento para a gestão ambiental. O Programa de Gestão de Áreas Contaminadas em Minas Gerais utiliza como ferramenta um cadastro que permite a definição de ações de gerenciamento e a elaboração do Inventário. O licenciamento representa uma etapa inicial de normalização ambiental para um empreendimento e pode ser entendido como a grande salvaguarda da qualidade e da conservação ambiental. Foi realizado um levantamento dos processos de licenciamento ambiental dos postos de combustíveis que estão na lista de áreas contaminadas do Estado de Minas Gerais de 2010. Grande parte dos postos de combustíveis apresentados na lista se encontra em situação indefinida de licenciamento ambiental. A investigação de passivos realizada durante o licenciamento foi responsável pela descoberta de processos de contaminação em diversos postos.

Palavras-chave: Áreas contaminadas; Licenciamento ambiental; Postos de combustíveis.

\section{THE MANAGEMENT OF CONTAMINATED AREA IN MINAS: LICENSING AS PREVENTIVE INSTRUMENT}

\section{ABSTRACT}

The concept of contaminated area is relatively recente in Brazil. Soil contamination involves risks to public health and ecosystems. It can be observed with great concern that the oil sector, whose activity is a potential contaminant, especially by leaking underground storage tanks at fuel stations. In the year 2010 were 439 contaminated sites listed in the State of Minas Gerais, and about $80 \%$ are related to the activities of fuel stations. This paper aims to discuss the management of contaminated areas in Minas Gerais. Like, describe the importance of licensing for environmental management. The Program Management of Contaminated Sites in Minas Gerais used as a tool to register contaminated areas, which allows the definition of management actions and the preparation of the inventory. The license represents an initial stage of a project for environmental standards and it can be understood as the great safeguard the quality and environmental conservation. Were conducted a survey of the processes of environmental licensing of petrol stations that are on the List of Contaminated Areas of Minas Gerais, 2010, which were analyzed. Most of the posts presents in the list is undefined in complicated situations or environmental licensing. The liabilities research conducted during the licensing was responsible for the discovery of contamination processes at different sites.

Key words: Contaminated areas; Environmental licensing; Fuel stations. 


\section{INTRODUÇÃO}

Diante da recente percepção do fenômeno de contaminação do solo, decorrente do seu uso inadequado como receptor ilimitado de substâncias nocivas descartáveis, com base no suposto poder tampão e potencial de autodepuração, se fez necessária a criação de ferramentas para a gestão e o gerenciamento de áreas contaminadas (Cetesb/ GTZ, 2001).

Até meados da década de 1970, o problema de contaminação de solos estava associado a alguns acidentes ambientais severos. Somente em 1980, foi criada, nos Estados Unidos, a primeira lei que tratava especificamente de áreas contaminadas e, portanto, da qualidade do solo (Epa, 1985). Desde então, a associação entre áreas contaminadas e atividades de deposição de resíduos industriais e distribuição e armazenamento de combustíveis passou a ser mais difundida. Assim, várias áreas contaminadas já foram e estão sendo identificadas em todo mundo.

O conceito de áreas contaminadas, descrito como um local cujo solo sofreu dano ambiental significativo que o impede de assumir suas funções naturais ou legalmente garantidas, representa o primeiro passo em direção à criação de estruturas políticas, legais e institucionais e serve para a conscientização de toda a sociedade no tocante ao uso e ocupação do solo (Sánchez, 2001).

É importante pontuar que na definição de áreas contaminadas deve haver uma preocupação em considerar não apenas a presença de poluentes, mas também a ocorrência de danos ou riscos aos bens a proteger, como a qualidade das águas em geral, dos solos e das águas subterrâneas, a saúde do indivíduo e da população como um todo.

A descoberta da dimensão do problema das áreas contaminadas e a pressão da sociedade levaram diversos países a desenvolver diferentes respostas para essa problemática, de maneira que tais respostas resultaram na elaboração de políticas, que objetivam equacionar os problemas relacionados às áreas contaminadas, por do uso de seus instrumentos de intervenção (Rodrigues Júnior, 2003).

No Brasil, é recente o conceito de áreas contaminadas, bem como seu gerenciamento. $\mathrm{O}$ Estado que se encontra mais avançado em relação à adoção de instrumentos de gestão para áreas contaminadas é São Paulo. A Companhia de Tecnologia de Saneamento Ambiental (Cetesb), órgão vinculado à Secretaria Estadual do Meio Ambiente do Estado de São Paulo, foi precursora na criação de diretrizes para o gerenciamento dessas áreas propostas no Manual de Áreas Contaminadas (Cetesb/ GTZ, 2001).

Segundo Sánchez (2001), o reconhecimento acerca da contaminação do solo como um problema ambiental que pode representar riscos à saúde pública e à vida ecológica só ocorreu após o amplo desenvolvimento de dispositivos legais e aparatos institucionais para lidar com a poluição da água e do ar.

A contaminação do solo, geralmente, se manifesta de maneira localizada, afetando, basicamente, regiões industrializadas, grandes concentrações urbanas ou regiões de agricultura intensiva. Além do mais, pode possuir algumas peculiaridades, tais como a questão da mobilidade e do poder cumulativo de seus poluentes. O grande problema da contaminação do solo está relacionado com a difícil detecção nos estágios iniciais. Diante dessa dificuldade, quando os efeitos da contaminação tornam-se evidentes, o dano já pode ter atingido níveis alarmantes, assim, a saúde da população pode se encontrar em risco, e, em consequência disso, as ações remediadoras tornamse urgentes (Silva, 2007).

Entre as principais adversidades decorrentes das áreas contaminadas, Sánchez (2001) relaciona os riscos com a segurança do indivíduo; das propriedades; com a saúde pública e dos ecossistemas; restrições ao desenvolvimento urbano e redução do valor imobiliário dos terrenos.

A definição de uma atividade como potencialmente contaminadora baseia-se, principalmente, na natureza das substâncias que são empregadas. Desta forma, é necessária a identificação dos produtos e resíduos gerados e dos processos produtivos empregados. Entre as inúmeras atividades com potencial para contaminar áreas, citam-se: o comércio atacadista de combustíveis, a extração de minerais; metalúrgica; agropecuária, o transporte ferroviário, rodoviário 
e aquiviário; a incineração e a deposição de resíduos, entre outros. Sendo assim, as principais fontes de contaminação são: os tanques de armazenamento, as atividades agrícolas, os aterros sanitários, lixões e depósitos industriais, cemitérios, as fossas sépticas e a disposição de rejeitos no solo, entre outras fontes (Epa, 2010).

Observa-se com muita preocupação o setor petrolífero. Um dos motivos é que a indústria do petróleo ainda constitui a principal fonte energética mundial, e os derivados do petróleo servem de matéria-prima para a manufatura de vários bens de consumo. Toda essa demanda exigiu grande estruturação da cadeia produtiva desse setor, desde novas descobertas de campos de petróleo, passando pela formação de vários pólos petroquímicos, até o aumento das redes de distribuição, a ponta dessa cadeia (Mariano, 2006).

Diante de toda estrutura logística da produção e comercialização do petróleo e de seus derivados, as preocupações relacionadas ao potencial de contaminação de solos e águas subterrâneas, principalmente, por vazamentos de tanques de armazenamento subterrâneos em postos de combustíveis, vêm crescendo (Fatorelli, 2005, Manenti et al, 2007)

Um grupo de poluentes altamente preocupantes e presentes nos derivados de petróleo são os hidrocarbonetos monoaromáticos, tais como benzeno, tolueno, etilbenzeno e xilenos, conhecidos como BTEX. São excessivamente tóxicos e seus constituintes têm maior solubilidade em água, portanto, são os poluentes com maior potencial de contaminar o lençol freático (Mariano, 2006). A presença dos hidrocarbonetos aromáticos no ambiente é um perigo tanto para a saúde pública quanto para o ecossistema, devido a sua toxicidade e habilidade de bioacumular ao longo da cadeia alimentar (Tiburtius, 2004). Os compostos BTEX são classificados como poluentes ambientais primários, pois são substâncias depressoras do sistema nervoso central, mutagênicas e carcinogênicas (Baird, 2002).

A Cetesb possui diversos instrumentos para a gestão de áreas contaminadas que auxiliam na tomada de decisão do governo estadual, e vêm disponibilizando, desde 2002, uma lista de áreas contaminadas no Estado de São Paulo. É interessante notar que no primeiro ano deste levantamento, existiam apenas 255 áreas contaminadas, quantia esta que se elevou para 3.675, conforme o levantamento de 2010. Este aumento considerável se deve a uma maior fiscalização, somadas com as ações de licenciamento sobre os postos de combustíveis; as fontes industriais, comerciais, de tratamento e disposição de resíduos; e ao atendimento aos casos de acidentes. Segundo a Cetesb, em 2010, os vazamentos em postos de combustíveis foram responsáveis por cerca de $80 \%$ dos casos de áreas contaminadas no Estado de São Paulo (Cetesb, 2011).

Em 2007, a Fundação Estadual do Meio Ambiente (Feam) divulgou a primeira lista de áreas contaminadas do estado de Minas Gerais, que continha 56 áreas. Em 2009, foi divulgada a segunda lista, bem mais expressiva que a primeira, contendo 413 áreas, e o primeiro inventário de áreas suspeitas de contaminação e contaminadas do Estado. No ano de 2010, a Feam divulgou o segundo inventário de áreas suspeitas de contaminação e contaminadas, e a terceira lista de áreas contaminadas e também reabilitadas do Estado de Minas Gerais. De acordo com a Gerência de Qualidade de Solos da Feam (Gesol), foram listadas 439 áreas contaminadas e, destas, 56 estão na condição de reabilitadas para usos específicos. Ainda segundo a Gesol, 247 áreas estão sob gerenciamento da Feam/Gesol e 192 estão sob responsabilidade da Prefeitura Municipal de Belo Horizonte/Secretaria Municipal de Meio Ambiente. Aproximadamente, 350 áreas foram contaminadas pela atividade de postos de combustíveis.

A deliberação normativa conjunta do Conselho Estadual de Política Ambiental (Copam)/Conselho Estadual de Recursos Hídricos (CERH-MG) nº 02/2010 instituiu o Programa Estadual de Gestão de Áreas Contaminadas que, por sua vez, estabeleceu as diretrizes e os procedimentos para a proteção da qualidade do solo e o gerenciamento ambiental de áreas contaminadas por substâncias químicas. No âmbito nacional, a Resolução do Conselho Nacional de Meio Ambiente (Conama) no 420/2009 dispõe sobre critérios e valores orientadores de qualidade do solo e estabelece diretrizes para o gerenciamento ambiental de áreas contaminadas. 
O número expressivo de áreas de postos de combustíveis também pode ser justificado pela ação de identificação de passivo ambiental realizada pela Feam e pela Secretaria Municipal de Meio Ambiente em atendimento à Resolução Conama $n^{\circ}$ 273/2000, à Deliberação Normativa Copam $n^{\circ}$ 108/2007, e a DN do Conselho Municipal de Meio Ambiente (Comam) no 32/2000, normas que impõem regras para o licenciamento dessa tipologia.

Este trabalho tem como objetivo analisar o gerenciamento de áreas contaminadas, principalmente no Estado de Minas Gerais, dando ênfase à problemática dos postos de combustíveis, além de descrever a importância do licenciamento para a gestão ambiental, e para a prevenção e/ou redução das áreas contaminadas.

\section{FUNDAMENTAÇÃO TEÓRICA}

\subsection{O gerenciamento de áreas contaminadas}

Em áreas contaminadas, os poluentes podem concentrar-se na subsuperfície, nas zonas nãosaturada e saturada. No momento em que um contaminante atinge o solo, vários mecanismos estão envolvidos, entre eles a adsorção, a fixação química, a oxidação, a troca iônica, a neutralização, a biodegradação ou o poluente pode ser arrastado pelas águas pelo escoamento superficial, ou lixiviado pelas águas de infiltração, passando para as camadas inferiores e atingindo as águas subterrâneas (Rodrigues; Duarte, 2003).

A maioria dos hidrocarbonetos é pouco solúvel em água, desta forma em um vazamento de derivados de petróleo, geralmente, ocorrem diversas fases de contaminação. Ao entrar em contato com o lençol freático, os hidrocarbonetos menos densos que a água se acumulam sob o topo do aquífero, formando a chamada fase livre. A fase residual ou adsorvida consiste no "rastro" de contaminação entre a fonte e o nível freático e caracteriza-se pela retenção dos coloides e dos compostos minerais do solo de uma pequena parcela destes hidrocarbonetos. A dissolução dos componentes solúveis presentes na fase livre do contaminante forma a fase dissolvida, possibilitando uma maior mobilização horizontal do composto. Outra fase observada é a de vapor, em que os componentes voláteis dos combustíveis formam uma fase gasosa que ocupa os poros do solo (Abdanur, 2005).

A definição precisa da fonte contaminante, com a estimativa da massa ou volume total, extensão da área afetada, e o tempo de lançamento do poluente no solo, é de extrema importância entre as ações iniciais no gerenciamento de áreas contaminadas. Realizada a avaliação e a caracterização da fonte, do contaminante e do solo, o passo seguinte é a avaliação do processo de contaminação, como a análise da extensão e da velocidade da pluma de contaminação, caso as águas subterrâneas sejam atingidas.

O gerenciamento de áreas contaminadas pode ser descrito como o conjunto de procedimentos e ações voltadas ao conhecimento de suas características e a definição das formas de intervenção mais adequadas, visando minimizar os danos e/ou riscos aos bens a proteger, gerados pela existência destas áreas (Conama, 2009).

A base para o gerenciamento das áreas contaminadas se estabelece em dois processos: o de identificação e o de recuperação. A identificação das áreas contaminadas tem como objetivo principal sua localização e envolve quatro etapas: a definição da área de influência; a identificação de áreas potencialmente contaminadas; a avaliação preliminar, e a investigação confirmatória. $\mathrm{O}$ processo de reabilitação/recuperação adota medidas de controle e correção nestas áreas, possibilitando recuperá-las para um uso compatível com as metas estabelecidas a serem atingidas após a intervenção. A recuperação é composta por seis etapas: investigação detalhada; avaliação de risco; investigação para remediação; projeto de remediação; remediação e monitoramento (Cetesb/ GTZ, 2001).

$\mathrm{Na}$ realização das etapas do processo de identificação, em razão do nível de informação existente referente a cada uma das áreas em estudo, estas podem ser classificadas como: áreas 
potencialmente contaminadas (APs); áreas suspeitas de contaminação (ASs) ou áreas contaminadas (ACs). As APs são aquelas em que estão sendo ou já foram desenvolvidas atividades potencialmente contaminadoras, ou seja, onde ocorre ou ocorreu o manejo de substâncias que podem causar danos e/ou riscos aos bens a proteger. As ASs são aquelas nas quais, durante a realização da etapa de avaliação preliminar, foram observadas falhas no projeto, problemas na forma de construção, manutenção ou operação do empreendimento, indícios ou constatação de vazamentos e outros. Uma AC pode ser definida resumidamente como a área ou terreno onde há comprovadamente contaminação (Cetesb/ GTZ, 2001).

A escolha das técnicas de avaliação de uma área contaminada é realizada, levando-se em considerações as características específicas de cada área a ser estudada. Entretanto, alguns procedimentos gerais são aplicáveis. Inicialmente, são levantados dados existentes sobre a geologia, pedologia, hidrogeologia e outros, visando indicar as características do fluxo das águas nas zonas não-saturada e saturada na área a serem investigadas, com o objetivo de definir os meios pelos quais os prováveis contaminantes irão se propagar. Em seguida, devem ser identificadas e determinadas as características dos contaminantes presentes, ou provavelmente presentes, na área (Silva, 2002; Silva, 2007).

A etapa de investigação confirmatória, que encerra o processo de identificação de áreas contaminadas, tem como objetivo principal confirmar ou não a existência de contaminação nas áreas suspeitas, identificadas na etapa de avaliação preliminar. O processo de confirmação se baseia na amostragem do solo e/ou água subterrânea, elaborada de acordo com os resultados obtidos na avaliação preliminar. Posteriormente, é feita a interpretação dos resultados das análises realizadas nas amostras coletadas pela comparação dos valores de concentração obtidos com os valores de concentração estabelecidos em listas de padrões, definidas pelo órgão responsável pelo gerenciamento de áreas contaminadas (Cetesb/ GTZ, 2001).

Em geral, no Brasil, são utilizadas três referências para valores orientadores de qualidade do solo, a Cetesb - Valores Orientadores para Solos e Águas Subterrâneas - 2005, as Normas Holandesas de classificação de solos - 1994, e a Resolução Conama n 420/2009. Em Minas Gerais, a recente Resolução Copam/Cerh $n^{\circ}$ 02/2010 também apresenta valores orientadores específicos para o estado.

Na Holanda, a classificação do solo é conforme os níveis de contaminação, de ocupação da área e dos riscos potenciais. Os solos são classificados em níveis S, I, ou T, sendo S considerado um solo não-contaminado; I, quando existe a necessidade de remediação; e T, um valor médio entre $\mathrm{S}$ e I, que indica a necessidade de investigações mais detalhadas. A Cetesb se baseia nas normas holandesas para as regulamentações da contaminação de solos e águas subterrâneas, determinando valores orientadores: Valor de Referência de Qualidade (VRQ), que é a concentração de determinada substância no solo ou na água subterrânea, que define um solo como limpo ou a qualidade natural da água subterrânea; Valor de Prevenção (VP), é a concentração de determinada substância, acima da qual podem ocorrer alterações prejudiciais à qualidade do solo e da água subterrânea, como exemplo, para o Benzeno o VP é $0,03 \mathrm{mg} \cdot \mathrm{kg}^{-1}$ de solo seco e; Valor de Intervenção (VI), onde existe a concentração de determinada substância no solo ou na água subterrânea acima da qual existem riscos potenciais, diretos ou indiretos, à saúde humana, para o Benzeno o VI é 0,08 mg. $\mathrm{kg}^{-1}$ de solo seco (Cetesb, 2005). A Resolução Conama n ${ }^{\circ}$ 420/2009 e a Copam/Cerh n ${ }^{\circ}$ 02/2010 também se baseiam em Valores Orientadores de Referência de Qualidade, de Prevenção e de Investigação.

Cabe ressaltar que o uso das normas holandesas de forma direta, pode levar à avaliações inadequadas, já que existem diferenças nas condições climáticas, tecnológicas e pedológicas de cada país. Os critérios das normas holandesas são diferentes em alguns pontos da Cetesb e da Resolução Conama $n^{\circ} 420$, pois consideram, por exemplo, os teores de umidade e de matéria orgânica na limitação dos distintos usos do solo.

Entre o processo de recuperação, as etapas, avaliação de risco, remediação e monitoramento, são as mais importantes. O objetivo principal da avaliação de risco é quantificar os riscos gerados 
pelas áreas contaminadas à saúde da população e aos ecossistemas. Essa quantificação é baseada em princípios de toxicologia, química e no conhecimento sobre o comportamento e transporte dos contaminantes. As atividades básicas de avaliação dos riscos são a identificação dos contaminantes principais e dos receptores, análise de exposição, análise dose-resposta, quantificação e gerenciamento dos riscos (Corseiul; Marins, 1997; Viana, 2010).

Nos Estados Unidos, a American Society for Testing and Materials desenvolveu em 2005, a Metodologia RBCA - Risk Based Corrective Action, descrita na ASTM E2081-00: Standard Guide for Risk-Based Corrective Action. Constitui um guia de ação corretiva baseada no risco para áreas contaminadas por tanques de armazenamento subterrâneos (ASTM, 2000). Esta norma está ganhando aceitação pela grande maioria dos órgãos estaduais de controle ambiental porque define regras claras para a avaliação dos locais contaminados com derramamento de petróleo. A análise baseada no risco significa que a remediação pode ser conduzida de maneira lógica, baseada na condição real que a contaminação apresenta para a sociedade. A análise de risco funciona como ferramenta de tomada de decisão. Quando o risco é aceitável, medidas de contenção e controle da contaminação podem ser eficazes, porém se o risco for inaceitável, a remediação se faz necessária. Assim, a alocação de recursos ocorre de forma mais racional (Finotti; Corseuil, 1997; Viana, 2010).

A etapa de remediação se baseia em medidas de contenção ou isolamento da contaminação e medidas de tratamento dos meios contaminados, visando à eliminação ou redução das concentrações de contaminação a níveis aceitáveis ou previamente definidos. Entre os objetivos de um programa de remediação de uma área contaminada, a redução da mobilidade, do volume e da toxicidade são primordiais. Contudo, o termo recuperação de áreas contaminadas envolve o princípio da "aptidão para um determinado uso", cujo objetivo é compatibilizar a área ao uso atual ou futuro (Silva, 2007).

O conhecimento da área contaminada, no que se refere ao meio físico, químico e biológico, com a informação das principais características do poluente em questão, é imprescindível para uma remediação eficaz da área (Brito et al., 2010). No que se refere ao tratamento de locais contaminados com hidrocarbonetos derivados do petróleo, uma grande variedade de processos físico-químicos e biológicos, tais como processos como extração de vapores do solo (SVE); pump and treat; extração multifásica; bioventilação; biosparging; incineração; adsorção em carvão ativado; biorreatores; landfarming; biorremediação in situ, entre outros, têm sido usados para remover contaminantes orgânicos de águas subterrâneas e dos sistemas de solo subsuperficial (Epa, 2009).

O gerenciamento de áreas contaminadas pode ser conduzido por um órgão federal, estadual, municipal ou, até mesmo, privado. Esse órgão é responsável pela execução das etapas do processo de identificação de áreas contaminadas e pela fiscalização da execução do processo de recuperação, que caberá ao responsável pela contaminação, de acordo com o princípio do "poluidor pagador" (Cetesb/Gtz, 2001; Brasil, 1981). É bastante elevado o dispêndio de recursos materiais, físicos, financeiros e humanos, sejam privados ou governamentais, para recuperar áreas contaminadas e minimizar os riscos aos bens a proteger (Sánchez, 2001).

O programa de Gestão de Âreas Contaminadas em Minas Gerais utiliza como principal instrumento o Banco de Declarações Ambientais (BDA). De acordo com a Deliberação Normativa Copam $n^{\circ} 116 / 2008$, os responsáveis por empreendimentos em áreas com suspeita de contaminação ou contaminadas devem fazer o cadastro junto à Feam. $\mathrm{O}$ cadastramento destas áreas permite a elaboração do inventário estadual de áreas suspeitas de contaminação e contaminadas e a definição do gerenciamento para cada área identificada, estabelecendo prioridades para fiscalização das áreas suspeitas e o acompanhamento das ações de investigação e reabilitação das áreas contaminadas. $\mathrm{O}$ inventário é uma importante ferramenta para divulgação à sociedade sobre os locais contaminados.

Revista de Gestão Social e Ambiental - RGSA, São Paulo, v. 6, n. 2, p. 19-32, maio/ago. 2012. 


\subsection{O licenciamento na gestão ambiental}

Segundo Azevedo (2006), a gestão ambiental envolve quatro pilares: a política, a legislação, o planejamento e a ação gerencial (governamental e privada). Entre as atividades da ação gerencial, destacam-se o licenciamento ambiental, atenção também dedicada à avaliação da qualidade ambiental, à fiscalização, à educação e à vigilância ambiental, às ações de emergência e à comunicação ambiental.

A concessão de uma licença ambiental e as condições a serem impostas ao empreendedor para que seu projeto possa seguir adiante, é o primeiro passo para uma gestão ambiental eficiente. $\mathrm{O}$ processo de avaliação de impacto ambiental tem implicações diretas nas futuras atividades de gestão ambiental de um determinado projeto. Do processo de AIA, resultam diretrizes e orientações para um programa de gestão (Sánchez, 2006).

O licenciamento representa uma etapa inicial de normalização ambiental para um empreendimento, é um processo decisório definido pelo órgão competente. A concessão de licenças ambientais denota que a empresa atuará de acordo com os preceitos de controle e proteção do meio ambiente, minimizando os impactos ambientais, e protegendo a saúde e o bem-estar da população. Assim, o licenciamento pode ser entendido como a grande salvaguarda da qualidade e da conservação ambiental (Azevedo, 2006).

Em postos revendedores e de abastecimento de derivados de petróleo, a obtenção da licença é vista como um instrumento de prevenção do dano ambiental, em que fica explícito o emprego de medidas preventivas de contaminação do solo e das águas superficiais e subterrâneas. No procedimento de licenciamento corretivo, julgam-se também, propostas de correção das nãoconformidades legais relativas à poluição (Bortoluzzi, 2004).

A Resolução Conama $n^{\circ}$ 237/1997 dispõe sobre a revisão e complementação dos procedimentos e critérios utilizados para o licenciamento ambiental. $\mathrm{O}$ art. $1^{\circ}$ desta resolução define que empreendimentos e atividades consideradas efetivas ou potencialmente poluidoras necessitam de licença decretada pelo órgão ambiental competente para a instalação, ampliação e a operação. Devido ao intenso potencial poluidor de postos de combustíveis, foi criada em 2000, a Resolução ${ }^{\circ}$ 273 do Conama, que dispõe especificamente sobre a instalação e operação de postos de combustíveis.

A Resolução $n^{\circ}$ 273/2000 considera que toda instalação e sistemas de armazenamento de derivados de petróleo configuram-se como empreendimentos, potencialmente ou parcialmente, poluidores e geradores de acidentes ambientais. Para tal, considera que os vazamentos de derivados de petróleo e outros combustíveis podem causar contaminação de corpos d'água subterrâneos e superficiais, do solo e do ar; considera os riscos de incêndio e explosões, decorrentes desses vazamentos; considera que a ocorrência de vazamentos vem aumentando significativamente nos últimos anos em decorrência da manutenção inadequada e da obsolescência do sistema; e considera a insuficiência e ineficácia de capacidade de resposta frente a essas ocorrências. Devido a tais considerações, o art. $1^{\circ}$ define que a localização, construção, instalação e operação de postos de combustíveis dependerão de prévio licenciamento do órgão ambiental competente, sem prejuízo de outras licenças legalmente exigíveis (Conama, 2000).

Em Minas Gerais, o licenciamento é realizado pela Feam, com exceção de Belo Horizonte e Contagem, cujo processo é coordenado pelas Secretarias Municipais de Meio Ambiente. Até 2005, apenas 11,2\% dos 4.266 postos de combustível cadastrados em Minas Gerais, junto à Feam possuíam licença ambiental, ou seja, 3.784 estabelecimentos funcionavam sem o prévio licenciamento ambiental previsto no art. $1^{\circ}$ da Deliberação Normativa do Conselho Estadual de Política Ambiental (Copam) nº 108/2007 (Feam, 2010).

A maioria dos tanques de armazenamento encontra-se alocada no subsolo, o que dificulta o monitoramento e o controle de vazamentos que, quando ocorrem, requerem medidas mitigadoras imediatas para evitar danos ao solo e a contaminação de águas subterrâneas. Isto é previsto na Resolução Conama n n $^{\circ}$ 273/1997 art. $8^{\circ}$ que declara que, em casos de acidentes ou vazamentos que

Revista de Gestão Social e Ambiental - RGSA, São Paulo, v. 6, n. 1, p. 19-32, maio/ago. 2012. 
representem situação de perigo ao meio ambiente ou as pessoas, os responsáveis pelo estabelecimento responderão solidariamente, pela adoção de medidas para controle da situação emergencial, e para o saneamento das áreas impactadas, no sentido de minimizar os riscos e os impactos às pessoas e ao meio ambiente.

No âmbito municipal, o Conselho Municipal de Meio Ambiente da Prefeitura de Belo Horizonte instituiu a Resolução Coman $n^{\circ} 32 / 2000$, que estabelece a convocação e as diretrizes para o licenciamento de postos de abastecimento de veículos e de revenda de combustíveis do município.

\section{MÉTODO DE PESQUISA}

Foi realizado um levantamento dos processos de licenciamento ambiental dos postos de combustíveis que estão na lista de áreas contaminadas do estado de Minas Gerais de 2010, sob gerenciamento da Supram Central (35 postos), e da Secretaria Municipal de Meio Ambiente da Prefeitura de Belo Horizonte (190 postos). Neste estudo, foi analisada a situação dos processos de licenciamento destes postos, bem como os relatórios ambientais apresentados.

As 247 áreas contaminadas gerenciadas pela Feam/Gesol estão distribuídas conforme Tabela 1:

Tabela 1: Áreas contaminadas gerenciadas pela Feam/Gesol distribuídas por Supram e atividade

\begin{tabular}{c|c|c|c|c|c|c|c|c|c|c}
\hline ATIVIDADE/SUPRAM & ASF & $\mathbf{C}$ & $\mathbf{J}$ & $\mathbf{L M}$ & $\mathbf{N R}$ & $\mathbf{N M}$ & $\mathbf{S M}$ & TM & ZM & Total \\
\hline Área órfã & - & - & - & - & - & - & - & - & 1 & $\mathbf{1}$ \\
\hline Bases de distribuição & - & 5 & - & - & - & 1 & - & 2 & - & $\mathbf{8}$ \\
\hline Dutos para transporte & - & 1 & - & - & - & - & - & - & - & $\mathbf{1}$ \\
\hline $\begin{array}{c}\text { Indústria Metalúrgica e } \\
\text { Siderúrgica }\end{array}$ & - & 15 & - & 3 & - & - & 2 & 1 & 1 & $\mathbf{2 2}$ \\
\hline Indústria Química & - & 3 & - & - & - & - & - & 1 & - & $\mathbf{4}$ \\
\hline Infraestrutura de & 2 & 2 & - & 3 & - & - & 2 & 1 & - & $\mathbf{1 0}$ \\
\hline Mineração & - & 8 & - & - & - & - & - & 1 & - & $\mathbf{9}$ \\
\hline Posto de Combustível & 18 & 35 & 5 & 31 & 2 & 10 & 29 & 23 & 26 & $\mathbf{1 8 9}$ \\
\hline Reciclagem de pilhas & - & - & - & - & - & - & - & 1 & - & $\mathbf{1}$ \\
\hline Transporte Ferroviário & - & 1 & - & - & - & - & - & 1 & - & $\mathbf{2}$ \\
\hline TOTAL & $\mathbf{2 0}$ & $\mathbf{7 2}$ & $\mathbf{5}$ & $\mathbf{3 7}$ & $\mathbf{2}$ & $\mathbf{1 0}$ & $\mathbf{3 3}$ & $\mathbf{3 0}$ & $\mathbf{3 8}$ & $\mathbf{2 4 7}$ \\
\hline
\end{tabular}

Fonte: Inventário de áreas suspeitas de contaminação e contaminadas do estado de Minas Gerais em 2010.

Nota: ASF: Supram Alto São Francisco; C: Supram Central; J: Supram Jequitinhonha; LM: Supram Leste Mineiro; NR: Supram Noroeste Mineiro; NM: Supram Norte de Minas; SM: Supram Sul de Minas; TM: Supram Triângulo Mineiro e ZM: Supram Zona da Mata.

A principal atividade é representada por postos de combustíveis (77\%). A maior parte das áreas contaminadas está concentrada na Supram Central (29\%), seguidas pelas Suprams da Zona da Mata e do Leste Mineiro (ambas 15\%); Sul de Minas (13\%); Triângulo Mineiro (12\%); Alto São Francisco (8\%); Norte de Minas (4,5\%); Jequitinhonha (2\%) e Noroeste Mineiro $(0,8 \%)$, conforme dados apresentados na Tabela 1.

As áreas contaminadas foram classificadas como Área Contaminada sob Intervenção (ACI) (38\%); Área Contaminada sob Investigação (AI) (31\%) e Áreas classificadas como Monitoramento para Reabilitação (AMR) (30\%). Apenas $2 \%$ das áreas contaminadas já foram Reabilitadas para o Uso Declarado (AR).

A distribuição das etapas de gerenciamento foi definida com base nos estudos realizados para as áreas contaminadas: Investigação Confirmatória (18\%); Investigação Detalhada/Análise de Risco (11\%); Projeto de Intervenção (3\%), Intervenção/Remediação (23\%) e Monitoramento $(45 \%)$. 
Das 192 áreas contaminadas sob gerenciamento da SMMA/PBH, 190 são áreas de postos de combustíveis. Dessas, 34 são classificadas como ACI; 25 áreas, como AI; 81, como AMR; e 50, como AR (Feam, 2010).

\section{RESULTADOS E DISCUSSÃO}

A situação dos 35 postos de combustíveis da lista de áreas contaminadas de 2010, sob gerenciamento da Supram Central, quanto ao licenciamento ambiental, está apresentada na figura 1 .

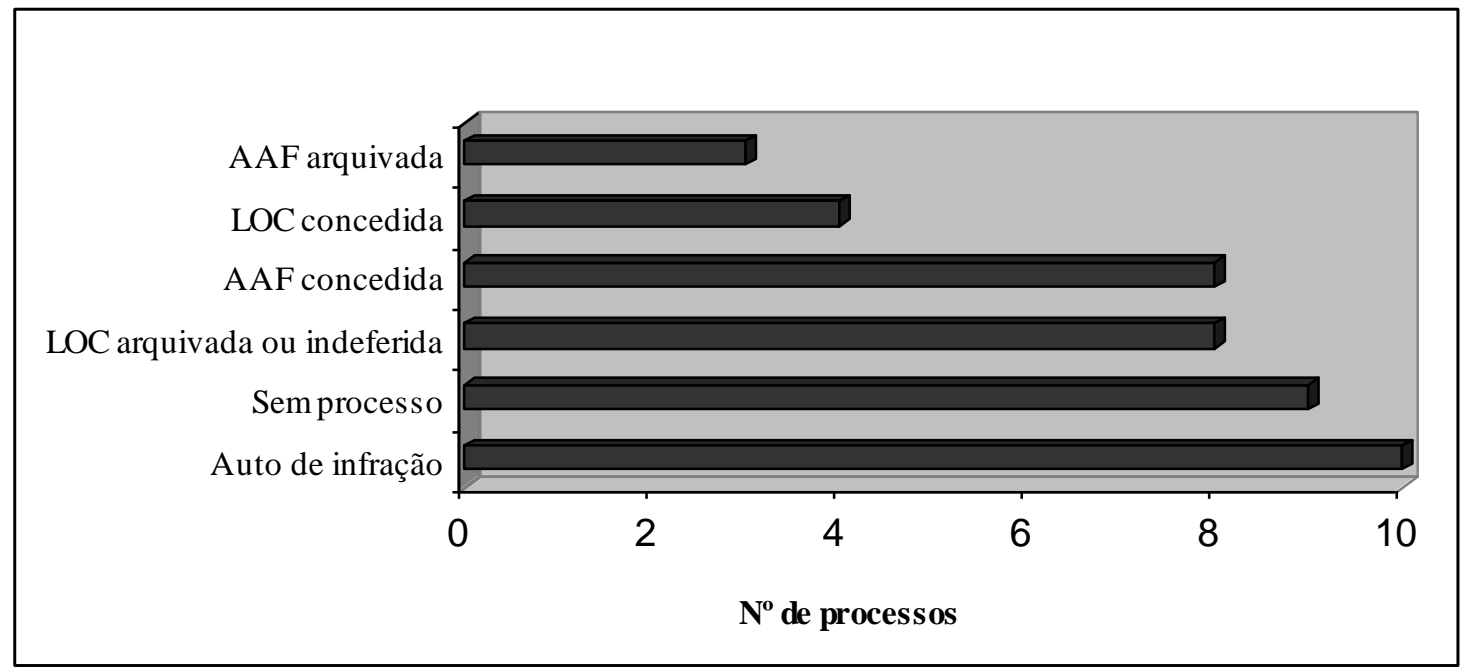

Figura 1: Situação dos processos de licenciamento dos postos gerenciados pela Supram Central. Nota: AAF: Autorização Ambiental de Funcionamento, LOC: Licença de Operação Corretiva

Nota-se que $34 \%$ dos postos requereram, primeiramente, a Licença de Operação corretiva, entretanto $23 \%$ não a obtiveram, sendo esta indeferida ou arquivada. Foi observado que com o parecer desfavorável da LOC, $75 \%$ dos postos nesta situação alteraram a classe do seu estabelecimento, modificando o porte ou as atividades desenvolvidas, e conseguiram, posteriormente, a concessão de AAF. Outros $26 \%$ dos postos observados não apresentam processo de licenciamento junto a Supram Central; 28\% demonstram Auto de infração; $10 \%$ tiveram a concessão de AAF negada; e 34\% conseguiram obter Licença ou AAF sem que antes tivessem algum processo arquivado ou indeferido. Como o procedimento para a obtenção de AAF é mais simplificado e menos criterioso, a maioria dos postos de combustíveis conseguiu, desta forma, uma regularização ambiental do órgão estadual. No entanto, é importante refletir que se estes postos não apresentaram condições para obter uma licença mais criteriosa como se pode confiar no controle e na gestão ambiental destes estabelecimentos?

A apresentação de relatórios anuais, tais como o de Verificação Metrológica do Inmetro, os de Programas de Automonitoramento, e de Testes de Estanqueidade, foi realizada em poucos processos, cerca de 30\%. Estes documentos são de extrema relevância para detecção e monitoramento de vazamento de tanques de armazenamento de combustíveis. A apresentação obrigatória do cronograma de troca de tanques ocorreu, na minoria das vezes, em menos de $40 \%$ dos processos. A maior parte dos processos também apresentou diversas solicitações de informações complementares, que nem sempre obtiveram respostas dos empreendedores.

Os Relatórios e os Planos de Controle Ambiental, RCA - PCA, apresentados para concessão da LOC, e, em alguns casos, para a AAF, se revelaram, na maioria das vezes, precários, pois apresentaram dados insuficientes e informações imprecisas sobre os riscos ambientais e os procedimentos de controle, principalmente, em relação à problemática mais expressiva dos postos de combustíveis, que é a questão do sistema de armazenamento de combustíveis. Nestes documentos, frequentemente não foi prestada a devida atenção aos métodos e instrumentos para 
detecção e ao monitoramento de vazamentos, que, usualmente, foram mal explicitados e detalhados. Foi observado, repetidas vezes, que alguns pontos citados nos Termos de Referência de RCA e PCA desta tipologia não foram estudados e descritos, tais como as especificações das instalações dos tanques de combustíveis; a investigação de passivos; a descrição e controle de ruídos; as propostas de tratamento e monitoramento dos efluentes líquidos; e das águas pluviais, entre outros. A maior parte dos relatórios não seguiu o padrão do Termo de Referência, e nem um padrão comum.

O levantamento de passivos, ou seja, possíveis vazamentos que ocorreram antes do requerimento da licença, foi demonstrado inferiormente à $40 \%$ dos PCAs, e nem sempre apresentaram estudos conclusivos, descrevendo apenas uma fase preliminar de investigação. A DN

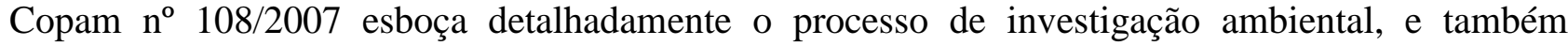
apresenta diretrizes para análise de risco. A questão dos resíduos perigosos, como os oleosos, foi mais definida e detalhada, a maioria dos relatórios dedica atenção ao programa de gerenciamento de resíduos e ao processo de separação e coleta do óleo. Os procedimentos de controle e prevenção de acidentes também foram bem explicitados.

Dos 190 postos da lista de áreas contaminadas de 2010 que estão sob gerenciamento da Secretaria Municipal de Meio Ambiente da PBH, 100 postos foram analisados quanto aos processos de licenciamento, na Gerência de Licenciamento de Comércio e Prestação de Serviços da SMMA PBH. Na Figura 2, apresenta-se a situação destes processos.

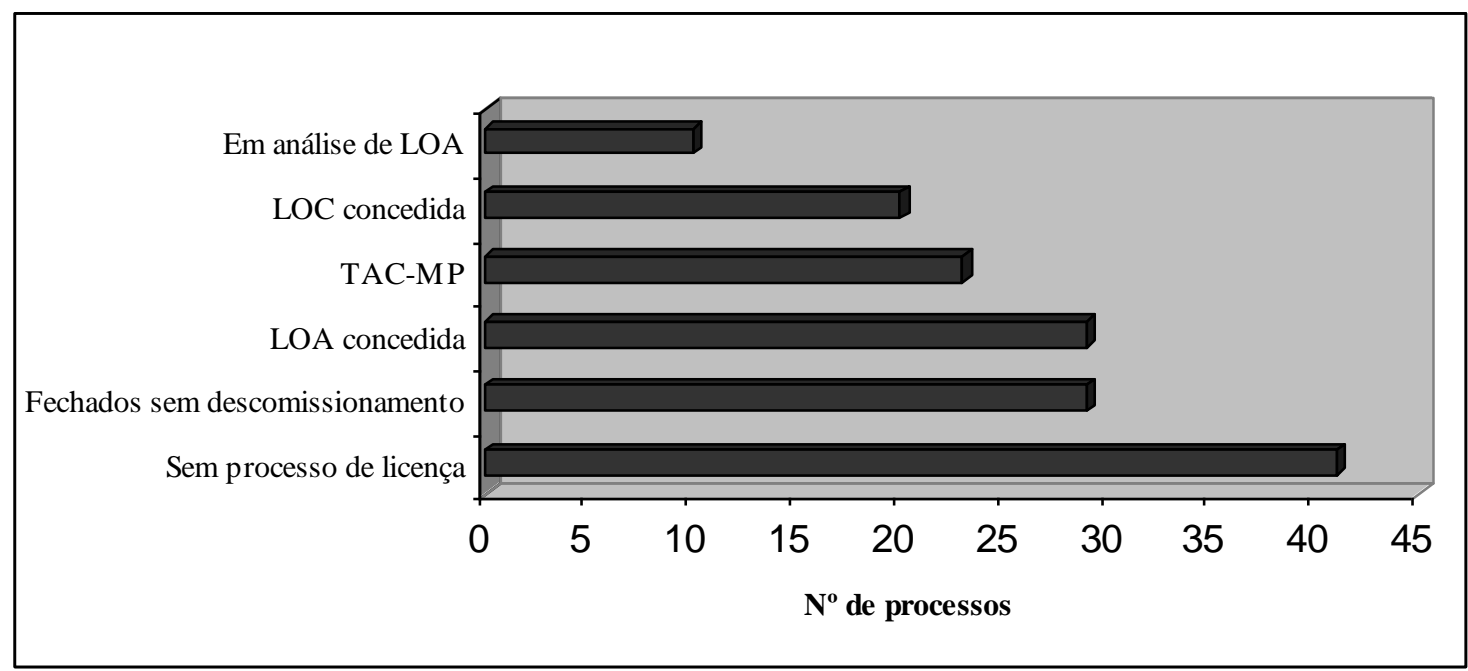

Figura 2: Situação dos processos de licenciamento dos postos gerenciados pela SMMA/PBH Nota: LOC: Licença de Operação Corretiva, LOA: Licença de Operação de Adequação, TAC-MP: Termo de Ajustamento de Conduta - Ministério Público.

Observa-se que $29 \%$ dos postos analisados possuem Licença de Operação de Adequação; $20 \%$ obtiveram Licença de Operação Corretiva; $10 \%$ se encontram em situação de análise de Licença de Operação de Adequação e $41 \%$ não possuem Licença Ambiental. Com relação aos postos sem licença, 52\% não apresentam processo junto a SMMA; 7\% tiveram a licença cancelada; $27 \%$ tiveram o requerimento de licença indeferido e $14 \%$ apresentam licença vencida. Foi visto que $29 \%$ dos postos analisados foram fechados sem descomissionamento, destes, $45 \%$ apresentavam LOC; $7 \%$ tinham LOA e $48 \%$ não possuíam Licença Ambiental. 23\% dos processos apresentam contrato de Termo de Ajustamento de Conduta- TAC com o Ministério Público.

Pode-se ressaltar que quase metade dos postos analisados não possui regularização ambiental. É considerável também, o número de postos que apresentam processo de TAC junto ao Ministério Público. 
A SMMA-PBH, em geral, é mais rígida quanto ao processo de licenciamento de postos de combustíveis que a Feam. A começar pela legislação, onde a DN Comam no 32/2000 é mais intransigente e criteriosa que a DN Copam n ${ }^{\circ}$ 108/2007, apesar de a última ser mais detalhada. No licenciamento municipal, os processos foram melhor analisados e os pareceres técnicos mais expressivos. A solicitação de informações complementares foi sempre excessiva, exigindo detalhamento ou a inclusão de itens do Termo de Referência.

Verificou-se que os relatórios ambientais foram mais padronizados que os apresentados à Feam, porém a maioria continuou sendo feito de maneira precária e apresentando dados insuficientes, o que provocou alto número de informações complementares e, por vezes, de condicionantes.

O certificado de estanqueidade e os relatórios de programas de monitoramento foram primordiais, para concessão de Licença de Adequação ou Corretiva de postos de combustíveis na SMMA. Atenção também foi prestada aos programas de investigação ambiental e análise de risco, e às propostas de atendimento à emergência.

Dos postos que realizaram a investigação de passivos ambientais, durante o processo de concessão de licença ou renovação, mais de $50 \%$ descobriram a existência de contaminação do subsolo. Desta forma, a intervenção, a remediação e o monitoramento foram solicitados pela SMMA no decorrer do processo. Se as propostas de intervenção, remediação e monitoramento são bem descritas, na maioria das vezes, a licença é concedida ou renovada, permanecendo como condicionante, a apresentação de relatórios de saneamento do solo e do lençol freático, com frequência mensal, trimensal, ou semestral, de acordo com a gravidade da contaminação.

\section{CONSIDERAÇÕES FINAIS}

Apesar dos 249 postos que estão na Lista de Áreas Contaminadas de 2010, sob gerenciamento da FEAM, apenas os 35 da Supram Central foram analisados. Mesmo sendo um grupo amostral pequeno, é possível inferir, sob outras justificativas, que grande parte dos postos apresentados na lista se encontra em situação complicada ou indefinida de licenciamento ambiental. O mesmo pode ser dito para os postos que se encontram sob gerência da SMMA-PBH. A investigação de passivos ambientais realizada durante o licenciamento foi responsável pela descoberta de processos de contaminação em diversos postos. Se não houvesse negligência, com a primeira ferramenta de proteção ambiental, que é o licenciamento, talvez muitos postos não estivessem inseridos na lista de áreas contaminadas, ou talvez a maioria já estivesse em condições de reabilitação.

Infelizmente, indica-se que ainda existem várias áreas contaminadas em Minas Gerais que não estão inseridas na lista da FEAM. Com o aumento da fiscalização, das ações de licenciamento ambiental, e da conscientização dos empreendedores sobre a importância da declaração de áreas contaminadas no Banco de Declarações Ambientais, a tendência é esta lista continuar aumentando. Supõe-se que muitos empreendedores acreditam que a declaração espontânea leve à penalização, enquanto outros temem os possíveis gastos da reabilitação da área. Contudo, o BDA é o instrumento mais efetivo do gerenciamento de áreas contaminadas da FEAM e, portanto, a colaboração dos empreendedores é primordial.

\section{REFERÊNCIAS}

Abdanur, A.(2005) Remediação de solo e água subterrânea contaminados por hidrocarbonetos de petróleo: estudo de caso na refinaria. Dissertação de mestrado em Ciências do Solo. Curitiba (PR): Universidade Federal do Paraná, 156 p.

ASTM E2081 - 00: Standard guide for risk-based corrective action. (2000) American Society for Testing and Materials (ASTM). 
Azevedo, F. A.(2006) Licenciamento ambiental: um campo de luta e indefinições. In: Nascimento, P. E., Viana, J. N. S. (Orgs.). Economia, meio ambiente e comunicação. Rio de Janeiro: Ed. Garamond, 113-122.

Baird, C.(2002) Química ambiental. Tradução de M. A. L. Recio e L. C. M. Carrera.(2. ed.) Porto Alegre, RS: Bookman.

Bortoluzzi, A. C. (2004) Gerenciamento ambiental dos postos de revenda de combustíveis líquidos: um estudo de caso. Dissertação de mestrado, Rio Grande do Sul: PPGEP, Santa Maria, Rio Grande do Sul, 2004. 81 p.

Brito, G. C. B. et al. (2010) A importância da bioprospecção de microrganismos em áreas contaminadas com produtos derivados do petróleo. Revista em Agronegócio e Meio Ambiente, 3(3), dez.

Companhia de Tecnologia de Saneamento Ambiental. (2005) Lista de valores orientadores para solos e águas subterrâneas. DECISÃO DE DIRETORIA Nº 195-2005- E, de 23 de novembro. Recuperado em 2 de janeiro de 2011, de:

<http://www.cetesb.sp.gov.br/solo/relatorios/tabela_valores_2005.pdf>.

Companhia de Tecnologia de Saneamento Ambiental. (2001) Manual de gerenciamento de áreas contaminadas. Projeto de Cooperação Técnica Brasil/ Alemanha - CETESB/ GTZ (Deutsche Gesellschaft fur Technische Zusammenarbeit). (2a ed.), São Paulo: CETESB, 389 p.

Companhia de Tecnologia de Saneamento Ambiental. (2011) Relação de áreas contaminadas Dezembro Recuperado em 3 de março de 2011, de: <http://www.cetesb.sp.gov.br/areascontaminadas/relacoes-de-areas-contaminadas/15-publicacoes $>$.

Conselho Estadual de Política Ambiental. (2008) Deliberação Normativa COPAM no 116 de 27 de junho de 2008. Dispõe sobre a declaração de informações relativas à identificação de áreas suspeitas de contaminação e contaminadas por substâncias químicas no Estado de Minas Gerais. Diário do Executivo de Minas Gerais, 28 jun.

Conselho Estadual de Política Ambiental. (2007) Deliberação Normativa COPAM no 108 de 24 de maio de 2007. Altera a Deliberação Normativa Copam 50/01, que estabelece os procedimentos para o licenciamento ambiental de postos revendedores, postos de abastecimento, instalações de sistemas retalhistas e postos flutuantes de combustíveis e dá outras providências. Diário do Executivo de Minas Gerais, 25 mai. 2007.

Conselho Estadual de Política Ambiental. (2010) Deliberação Normativa Conjunta COPAM/ CERH $n^{\circ} 02$ de 08 de setembro de 2010. Institui o Programa Estadual de Gestão de Áreas Contaminadas, que estabelece as diretrizes e procedimentos para a proteção da qualidade do solo e gerenciamento ambiental de áreas contaminadas por substâncias químicas. Diário do Executivo de Minas Gerais, 09 set. 2010.

Conselho Municipal de Meio Ambiente. (2010) Deliberação Normativa COMAM n 32 de 13 de setembro de 2000. Inclui os estabelecimentos revendedores de combustíveis veiculares na relação de empreendimentos de impacto e dá outras providências. Diário Oficial do Município, 14 set. 2000 . 
Conselho Nacional do Meio Ambiente. (2007) Resolução Conama $n^{\circ} 237$ de 19 de dezembro de 1997. Dispõe sobre licenciamento ambiental; competência da União, Estados e Municípios; listagem de atividades sujeitas ao licenciamento; Estudos Ambientais, Estudo de Impacto Ambiental e Relatório de Impacto Ambiental. Diário Oficial da União, 20 dez. 1997.

Conselho Nacional do Meio Ambiente. (2000) Resolução Conama $n^{\circ} 273$ de 29 de novembro de 2000. Dispõe sobre licenciamento de postos revendedores, postos de abastecimento, intalações de sistemas retalhistas e postos flutuantes de combustíveis. Diário Oficial da União, 30 nov. 2000.

Conselho Nacional do Meio Ambiente. (2009) Resolução Conama $n^{\circ} 420$ de 30 de dezembro de 2009. Dispõe sobre critérios e valores orientadores de qualidade do solo quanto à presença de substâncias químicas e estabelece diretrizes para o gerenciamento ambiental de áreas contaminadas por essas substâncias em decorrência de atividades antrópicas. Diário Oficial da União, 31 dez. 2009.

Fatorelli, L.(2005) Proposta de avaliação de risco ecológico para contaminações de petróleo e derivados -Estudo de caso. 2005. Dissertação (Mestrado em Engenharia Ambiental) - Universidade Federal de Santa Catarina, Florianópolis.

Finotti, A. R., Corseuil, H. X. (1997) Uso da ação corretiva baseada no Risco - RBCA - nos casos de contaminação de solos e águas subterrâneas por gasolina no Brasil. Congresso Brasileiro de Engenharia Sanitária e Ambiental, 19.

Fundação Estadual do Meio Ambiente - Feam. (2010) Inventário de áreas suspeitas de contaminação e contaminadas do Estado de Minas Gerais de 2010. Recuperado em 15 de janeiro de 2011, de:

<http://www.feam.br/images/stories/inventario/areascontaminadas2010/inventario_de_reas_suspeit as_e_contaminadas_2010.pdf >.

Fundação Estadual do Meio Ambiente - Feam (2009) Inventário de áreas suspeitas de contaminação e contaminadas do Estado de Minas Gerais de 2009. Recuperado em 15 de janeiro de 2011, de:

<http://www.feam.br/images/stories/alvaro/inventario\%20areas\%20susp_cont_e_cont_2009.pdf>.

Fundação Estadual do Meio Ambiente - Feam (2010) Lista de áreas contaminadas do Estado de Minas Gerais de 2010. Recuperado em 15 de janeiro de 2011, de:

<http://www.feam.br/images/stories/arquivos/areas_contaminadas/2011/lista_acr_2010_municipio. pdf $>$.

Fundação Estadual do Meio Ambiente - Feam(2009) Relatório de lista de áreas contaminadas do Estado de Minas Gerais de 2009. Recuperado em 15 de janeiro de 2011, de:

<http://www.feam.br/images/stories/arquivos/areas_contaminadas/AREAS_2009/relatorio_lista_ac _2009.pdf $>$.

Mariano, A. P. (2006) Avaliação do potencial de biorremediação de solos e de águas subterrâneas contaminados com óleo diesel. 2006. Tese (Doutorado em Geociências e Ciências Exatas) Universidade Estadual Paulista, Rio Claro.

Manenti, R. D. et al.(2007) Aplicação de barreira reativa permeável na redução da contaminação por vazamentos em tanques de combustíveis. Revista Tecnológica, 16, 45 - 51. 
Política Nacional do Meio Ambiente (1981) Lei 6.938 de 31 de agosto de 1981. Diário Oficial da União, 30 ago.

Rodrigues JR, J. J.(2003) Proposta metodológica para gerenciamento de áreas contaminadas: uma Aplicação no estado do Rio de Janeiro. Dissertação de Mestrado, Rio de Janeiro:

PPE/COPPE/UFRJ.

Rodrigues, S., Duarte, A. C. (2003) Poluição do solo: revisão generalista dos principais problemas. In: Castro, A.; Duarte, A.; Santos, T. (Ed.). O ambiente e a saúde. Lisboas: Instituto Piaget, 136 176.

Sánchez, L. E.(2006) Avaliação de impacto ambiental e seu papel na gestão de empreendimentos. In: Vilela Jr, A., Demajorovic, J. (Orgs.). Modelos e ferramentas de gestão ambiental: desafios e perpectivas para organizações. São Paulo: Ed. Senac São Paulo, 85-115.

Sánchez, L. E. (2001) Desengenharia: o passivo ambiental na desativação de empreendimentos industriais. Editora da Universidade de São Paulo, São Paulo, 254p.

Silva, J. A. F. (2002) Sistematização e avaliação de técnicas de investigação aplicadas à caracterização e diagnóstico de área contaminada por hidrocarbonetos de petróleo. 2002. Dissertação (Mestrado em Geociências e Meio Ambiente) - Universidade Estadual Paulista, Rio Claro.

Silva, R. F. G. (2007) Gestão de áreas contaminadas e conflitos ambientais: o caso da cidade dos meninos. Dissertação de Mestrado, Rio de Janeiro: PPE/COPPE/UFRJ, 110 p.

Tiburtius, E. R. L. et al. (2004) Contaminação de águas por BTXs e processos utilizados na remediação de sítios contaminados. Química Nova, 27, 441-446.

United States Environmental Protection Agency (Epa). (2009) How to evaluate alternative cleanup technologies for underground storage tank sites. Recuperado em 30 de outubro de 2010, de:< http://www.epa.gov/oust/pubs/tums.htm >.

United States Environmental Protection Agency (Epa). Soils policy: soil contamination in Europe. Recuperado em 15 de outubro de 2010,

de:<http://www.epa.gov/oswer/international/factsheets/200906_eu_soils_contamination.htm>.

United States Environmental Protection Agency (Epa).(1985) The Birth of EPA. EPA Journal. Recuperado em 2 de novembro de 2010, de:〈http://www.epa.gov/history/topics/epa/15c.htm>.

Viana, D. B. (2010) Avaliação de riscos ambientais em áreas contaminadas: uma proposta metodológica. 2010. Dissertação (Mestrado em Planejamento Energético) - COPPE/UFRJ, Rio de Janeiro.

Data do recebimento do artigo: 08/07/2011

Data do aceite de publicação: 10/08/2012 